\title{
A SUSTAINABLE ECONOMY
}

\begin{abstract}
Joel J. Pawlak
There exists a direct correlation between improvements in standard of living and the consumption of resources. To be able to maintain the standard of living of a modern developed country, society must adapt to an economy based on sustainable processes, energy, and raw materials. The sustainable economy presents itself as a disruptive technology to the traditional economy, which is based largely on non-renewable resources. The issue seems to be more about when will we switch to a sustainable economy, rather than whether we will switch.
\end{abstract}

Keywords: Sustainable, Disruptive Technology, Environment, Economic Growth

Contact information: Department of Forest Biomaterials Science and Engineering, North Carolina State University, Raleigh, North Carolina 27695 USA; mailto:jipawlak@ncsu.edu

The continuing evolution of the environmental movement, which originated in the 1960 s and 1970s, is leading us to a new understanding of what it will mean to achieve environmental compatibility. The evolving paradigm is simply called sustainability. It is not really a new concept, but it is a concept which industry is now beginning to embrace. In this editorial, I will discuss why the environmentalist can support sustainability, why industry can support sustainability, and why sustainability is a necessary condition for developed economies. This issue is closely linked to our bioresources, as they constitute a valuable source of sustainable raw materials.

The idea of having a lower impact on the environment is an idea that nearly everyone can embrace. Conflicts embodied in the term "environmentalism" mainly arise when one finds that consumption needs to be curtailed to achieve environmental goals. In fact, nearly everything we consume ultimately becomes waste. On the planet Earth, for the most part, there is a constant amount of mass. We cannot create or destroy any significant amount of mass. Once a product is consumed, it will have a limited amount of "useful life" before it is rendered as waste. The "useful life" could just be a few short minutes, such as for a paper cup, or a few hundred years, as with a house. In the end, once something reaches the end of its useful days, it becomes waste. This means that as consumption increases, so does the amount of waste generated. While some elements in our society will reduce consumption for the sake of the environment, the vast majority of society constantly strives to improve its standard of living - this can be read as increasing consumption. In fact, the majority of the world strives to greatly elevate its standard of living. Thus, the simple solution to reducing environmental impact is to reduce consumption, which is not a realistic expectation.

To improve the environmental performance of society, there is only one realistic solution. This solution is sustainability. In an ideal sense, sustainability could be simply defined as zero waste. This would mean that as something is consumed, it becomes the raw material for something else. This concept is not novel, but it has subtlety that insures

Pawlak (2007). "A sustainable economy," BioResources 3(1), 1-2. 
that our need for raw materials is perpetually satisfied. At some point in time, our nonrenewable resources will limit our ability to expand the economy, and a transition to a sustainable economy will happen. Chances are, the transition, as it happens, will not be perceivable to most people. In all likelihood, we will transition to a sustainable economy due to economic pressures and not societal demands.

The three phases of the traditional technology cycle are well known. Together, they constitute what is often called the technology S-curve. This description relates the performance of a technology as a function of the effort invested in the technology. Traditional technologies typically follow this kind of behavior - initial slow progress, followed by large gains in performance, and then an era of limited returns for efforts. I would suggest that sustainable technology is poised to be a disruptive technology. A disruptive technology is a technology that measures its value by a metric different than the existing technology. However, over time, the disruptive technology meets the performance of the existing technology, and then rapidly displaces the existing technology. Applying these concepts to traditional unsustainable technology, one can expect that when traditional technology's performance erodes due to limited resources and rising raw materials costs, sustainable technologies will rapidly replace the existing technology.

The threat of sustainable technology rapidly displacing existing technology is why industry should be interested in sustainability today. Often, the existing business cannot see the disruptive technology coming, because the disruptive technology does not yet perform at the level of the existing technology. The world of business is littered with companies cast aside by their best customers when disruptive technology is in play (Christensen 1997).

The question then simply becomes, when will sustainable technology become competitive with the existing technology? This question is yet to be answered. However, it is currently known that gasoline and other non-renewable fuels are at all-time high prices. It is also known that the pricing of many raw materials derived from nonrenewable resources is increasing with no foreseeable reduction in price forthcoming. It is also known that Chinese economy has awakened. In the last few years, more than one billion people in Asia have gained access to the world economy, placing an even larger burden on the world's non-renewable resources. Taking these factors into account, it would seem that the traditional means for improving economic performance in industry by cutting raw material and process costs, may be coming to an end - that is to say, we are in the third phase of the technology S-curve for traditional industry. The time for the sustainable economy may be nearer than we think.

\section{Reference Cited}

Christensen, C. (1997). The Innovator's Dilemma When Technologies Cause Great Firms to Fail, Harvard Business School Press, Boston, Mass. 